\title{
Rotator Cuff Reconstruction and Humeral Head Replacement Using Smaller Humeral Prostheses in Cuff Tear Arthropathy Patients under 70 Years of Age
}

\author{
Naoki Miyoshi' ${ }^{1}$, Naoki Suenaga ${ }^{2}$, Naomi Oizumi², Noboru Taniguchi ${ }^{3}$, Hiroshi Ito ${ }^{1}$ \\ ${ }^{1}$ Department of Orthopaedic Surgery, Asahikawa Medical University, Asahikawa, Japan \\ ${ }^{2}$ The Upper Extremity Center of Joint Replacement and Endoscopic Surgery, Hokushin Hospital, \\ Sapporo, Japan \\ ${ }^{3}$ Department of Orthopaedic Surgery, Miyazaki University, Miyazaki, Japan \\ Email: mnao@asahikawa-med.ac.jp
}

Received 15 August 2014; revised 30 September 2014; accepted 16 October 2014

Copyright (C) 2014 by authors and Scientific Research Publishing Inc.

This work is licensed under the Creative Commons Attribution International License (CC BY). http://creativecommons.org/licenses/by/4.0/

(c) (i) Open Access

\section{Abstract}

Background: Most reverse shoulder arthroplasty (RSA) studies have shown good improvement in arm elevation without improvements in external rotation (ER). In addition, high rates of complications after long-term RSA have been reported, suggesting that RSA should be limited to elderly patients, especially those who are older than 70 years old. Since 2001, we have developed a strategy of rotator cuff reconstruction with muscle transfer and humeral head replacement (HHR), using smaller humeral prostheses, in cuff tear arthropathy patients. The aim of the present study was to investigate the clinical outcome of our strategy in patients under 70 years of age who had irreparable rotator cuff tears and osteoarthritis. Materials and Methods: A total of 25 shoulders of 25 patients under 70 years of age (males, 15; females, 10) with irreparable cuff tears were treated with HHR and cuff reconstruction. The average age at the time of surgery was 64.3 years (range, 55 - 69) and the average follow-up period was 38.7 months (range, 24 - 72). The cuff defect was repaired using a partial subscapularis transfer in 14 shoulders; nine shoulders required a latissimus dorsi transfer, one required a pectoralis major transfer, and one required both a latissimus dorsi and a pectoralis major transfer. Clinical outcomes were assessed with the range of motion (ROM), UCLA score, Japanese Orthopaedic Association (JOA) score and postsurgical complications. Results: Shoulder pain was diminished in all patients after surgery. The preoperative UCLA and JOA scores were 13.1 and 47.0 respectively, improving to 28.6 and 81.5 respectively after surgery. Active forward flexion has improved from an average of $89.0^{\circ}$ to $138.8^{\circ}$, and the ER improved from an average of $16.2^{\circ}$ to $33.2^{\circ}$. No complications occurred after surgery. Conclusion: Anatomical reconstruction using smaller head humeral prostheses yielded favorable results and less complication, 
compared with RSA. Considering another advantage of ability to retain glenoid bone stock, the current procedure can be a useful option for irreparable rotator cuff tears with $0 \mathrm{~A}$ in patients under 70 years old.

\section{Keywords}

\section{Irreparable Rotator Cuff Tear, Cuff Reconstruction, Cuff Tear Arthropathy, Humeral Head Replacement Using a Small Head}

\section{Introduction}

Cuff tear arthropathy is a difficult shoulder joint problem. Recently, reverse shoulder arthroplasty (RSA) has been performed worldwidely [1]-[6] with many RSA studies showing good improvements in arm elevation. However, Favard et al. [2] noted that the Constant-Murley score was less than 30 points in $72 \%$ at 10 years after RSA. Furthermore, high rates of complications, such as deltoid rupture, glenoid loosening, infection, neurologic injury, dislocation, acromial fracture, and breakage of the prosthesis, can occur over the long-term after RSA. Therefore, Boileau et al. [1] suggested that RSA should be limited to elderly patients, especially those over 70 years of age. It is thus necessary to consider alternative treatment option for younger patients with irreparable rotator cuff tear with osteoarthritis (OA). In order to solve this problem, since 2001, we have developed a strategy [7] to use a smaller humeral head for humeral head replacement (HHR) combined with cuff reconstruction using remained subscapularis and teres minor, or tendon transfers. Using a smaller head allows easier reconstruction of rotator cuff defects and medial shift of the center of rotation of the shoulder joint, which increases the lever arm of the deltoid muscle. The aim of the present study was to investigate the clinical outcomes of our strategy in patients under 70 years of age who had irreparable rotator cuff tears and OA.

\section{Patients and Methods}

This retrospective study involved 25 shoulders ( 17 right; 8 left) of 25 patients under 70 years of age (15 males; 10 females) with irreparable cuff tears that were treated with HHR and cuff reconstruction. The follow-up was performed over a period of more than 24 months.

\subsection{Surgical Procedure}

All procedures were performed on patients in a beach-chair position under general anesthesia with a preoperative interscalene block. A superior deltoid splitting approach between the anterior and middle fibers with preservation of the coracoacromial arch was performed. Approximately $5 \mathrm{~mm}$ of the lateral side of the acromion was resected to promote better healing of the repaired deltoid muscle, and the humeral head was exposed. After confirming the size of the rotator cuff tear and evaluating the humeral head cartilage, HHR was performed when it was not possible to suture the torn rotator cuff tendon to the top of the humeral head even after intra- and extra-articular mobilization of the cuff and the humeral head showed OA changes. After resection of the humeral head at the level of anatomical neck, with guidance provided by the collar of the trial stem, the stem was inserted with a $40^{\circ}$ angle of retroversion (Figure 1(a)). The retroversion should be greater than that for usual humeral head replacement with intact cuff tendons to avoid antero-superior escape of the head. Impaction bone grafting was performed during humeral stem insertion using cancellous bone from the resected humeral head and an artificial bone tip (HA) (Figure 1(b)). At this point, the size of the humeral head was determined. A head with a diameter that matched the osteotomy surface was initially selected; this was usually one-size smaller than the original head because the humeral head diameter of the affected shoulder is usually larger than that of the unaffected side. If the cuff could not be repaired with the selected humeral head, a thinner head with the same diameter was then tried, and next, if necessary, a thinner head with a smaller diameter (at most $4 \mathrm{~mm}$ smaller) was tried (Figure 1(d)). However, an even smaller head should not be used to avoid too much incongruity and instability between the head and the glenoid. Fluoroscopy was used to confirm that the greater tubercle was not higher than the selected humeral head. When the greater tubercle appeared to be higher (Figure 1(c)), it was shaved to an appropriate height. If the cuff could still not be repaired with a smaller and thinner head, tendon 

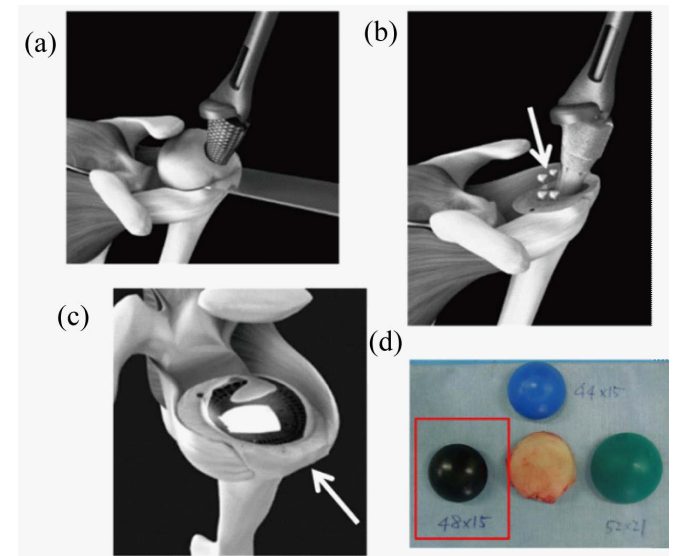

\begin{abstract}
Figure 1. Operative image of humeral head replacement: (a) Resection of the humeral head under the guidance of a trial stem; (b) A humeral stem inserted at $40^{\circ}$ retroversion with impaction bone grafting using cancellous bone from the resected humeral head and an artificial bone tip (HA). White arrow: bone grafting using cancellous bone from the resected humeral head and an artificial bone tip; (c) The height of the humeral head prosthesis and greater tubercle measured radiographically. White arrow: The greater tubercle is higher than the humeral head prosthesis; (d) The size of the humeral head was determined. A head with a diameter that matched the osteotomy surface was initially selected; this was usually one-size smaller than the original head. If the cuff could not be repaired with the selected humeral head, a thinner head with the same diameter was then tried, and next, if necessary, a thinner head with a smaller diameter (at most $4 \mathrm{~mm}$ smaller) was tried.
\end{abstract}

transfers were considered as an adjunctive procedure. In most cases in this series, the supraspinatus and infraspinatus tendons were torn and remarkably retracted, and show severe degeneration and atrophy. In cases in which the subscapularis and teres minor tendons remained intact, two thirds of the superior aspect of the intact subscapularis muscle was detached subperiosteally (Figure 2(a)) and transferred antero-superiorly while the intact teres minor tendon was lifted postero-superiorly. The teres minor and subscapularis tendons were side-toside sutured and then sutured laterally to the greater tubercle (Figure 2(b) and Figure 2(c)). Furthermore, if possible, the supraspinatus and infraspinatus tendons were sutured at the medial site of the transferred subscapularis and teres minor tendon (Figure 2(d)). If the anterosuperior part of the rotator cuff including the subscapularis was deficient, a pectoralis major transfer was performed to cover the defect, adding the deltopectoral approach and passing the pars sternocostalis of the pectoralis major tendon under the conjoined tendon. If the posterosuperior part of the rotator cuff including the teres minor was deficient, a latissimus dorsi transfer was performed with an anterior approach, and the latissimus dorsi tendon was passed under the deltoid muscle.

The cuff defect was primarily repaired, including a partial subscapularis transfer, in 14 shoulders; nine shoulders required a latissimus dorsi transfer, one required a pectoralis major transfer, and one required both a latissimus dorsi and a pectoralis major transfer.

\title{
2.2. Postoperative Treatment
}

An abduction pillow was used for eight weeks postoperatively. Active elevation in a sitting position from the adducted position of the shoulder was permitted after 10 weeks, and isometric cuff exercises were initiated at 12 weeks. The patients were allowed to resume heavy work after sufficient muscle strength was evident, along with range of motion (ROM) recovery, at six months or more postoperatively (Figure 3).

\subsection{Clinical Evaluation}

Clinical outcomes were assessed using the following criteria: ROM (active flexion, active external rotation [ER] and internal rotation [IR]); the University of California, Los Angeles shoulder score (UCLA score); the shoulder score of the Japanese Orthopaedic Association (JOA score) (Table 1); complications due to surgery.

Statistical analysis of the preoperative and postoperative data was performed using paired $t$-test. $\mathrm{P}$ values $<$ 


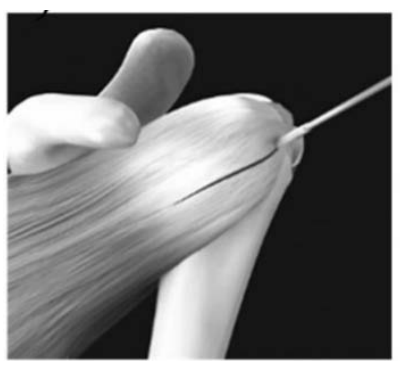

(a)

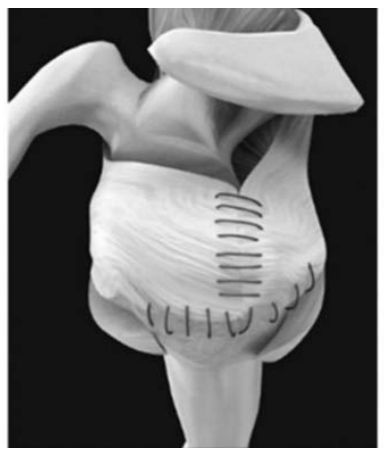

(c)

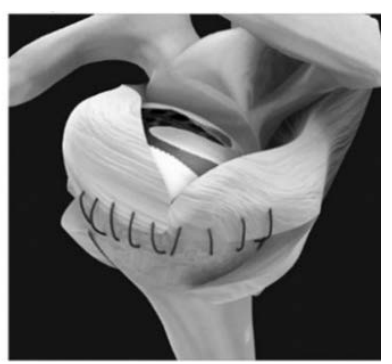

(b)

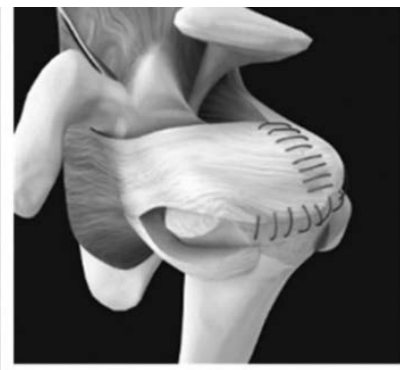

(d)

Figure 2. Operative image of cuff reconstruction: (a) Two thirds of the superior aspect of the intact subscapularis and teres minor tendon has been detached subperiosteally; (b) and (c) The intact teres minor tendon has been lifted postero-superiorly while the subscapularis tendon, with a partially resected attachment site, has been lifted anterio-superiorly. The teres minor and subscapularis tendons have been side-to-side sutured and then sutured laterally to the greater tubercle; (d) If possible, the supraspinatus and infraspinatus tendons were sutured at the medial site of the transferred subscapularis and teres minor tendon.

\begin{tabular}{|c|c|c|c|c|c|c|c|c|c|}
\hline & & & & $\mathrm{me}$ & & & & & \\
\hline & Uperation day & 1 & 2 & 4 & 6 & 8 & 10 & 12 & $\ldots \ldots$. \\
\hline & & & & & & & & & \\
\hline Abduction pillow & & & & & & & & & \\
\hline Passive ROM exercise & & & & & & & & & \\
\hline (except extention an & & & & & & & & & \\
\hline & & & & & & & & & \\
\hline Active ROM exercise ( & & & & & & & & & \\
\hline in a Supine pos & & & & & & & & & \\
\hline in a Sitting pos & & & & & & & & & \\
\hline Isometric cuff exercize & & & & & & & & & \\
\hline & & & & & & & & & \\
\hline
\end{tabular}

Figure 3. The protocol of postoperative treatment.

0.05 was considered significant.

\section{Results}

In this study, the average patient age was 64.3 years (range, 55 - 69 years) and the average follow-up period was 38.7 months (range, 24 - 72 months) (Table 2). One of the patients (Table 2, Case 3) had history of a shoulder dislocation. All patients reported none or mild shoulder pain after surgery. The mean preoperative UCLA and JOA scores were 13.1 points (range, 6 - 19) and 47.0 points (range, 13 - 79.5), respectively, and both significantly improved at the final follow-up to 28.6 points (range, 16 - 34) and 81.5 points (range, 59 - 93), respectively ( $\mathrm{P}<0.0001$ for both score improvements). Active forward flexion improved from an average of $89.0^{\circ}$ to 
Table 1. Japanese Orthopaedic Association (JOA) score.

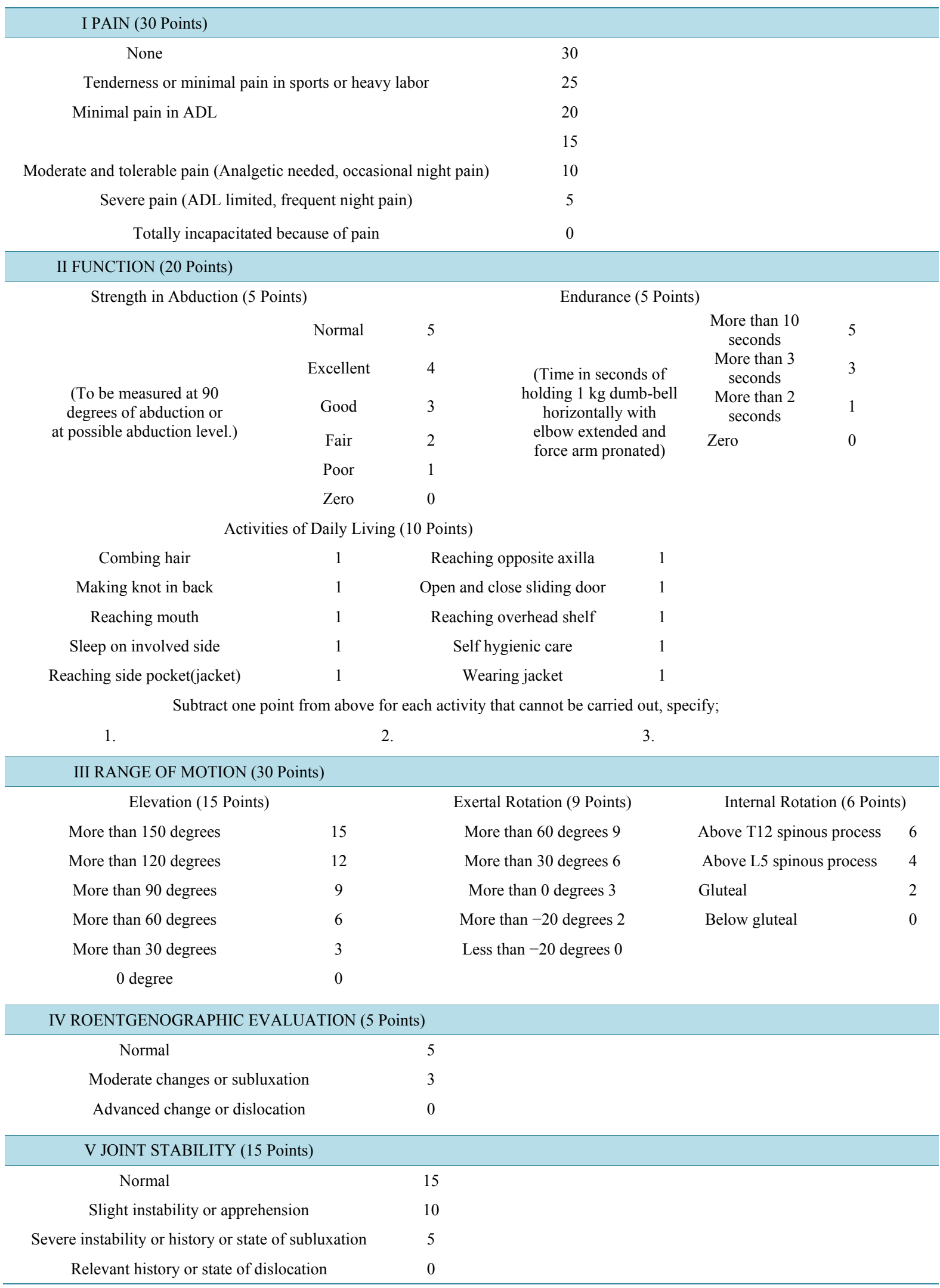


Table 2. All cases in the present study.

\begin{tabular}{|c|c|c|c|c|c|c|c|}
\hline Case & Follow-up & Age & Sex & Disease & $\begin{array}{c}\text { Hamada } \\
\text { classification }\end{array}$ & $\begin{array}{c}\text { Seebauer } \\
\text { classification }\end{array}$ & Surgical methods \\
\hline 1 & 40 & 60 & M & Cuff tear arthropathy & 1 & I A & HHR \\
\hline 2 & 72 & 64 & $\mathrm{~F}$ & Cuff tear arthropathy & 1 & I A & $\mathrm{HHR}+\mathrm{LD}$ \\
\hline 3 & 62 & 58 & $\mathrm{~F}$ & Cuff tear arthropathy & 1 & I A & $\mathrm{HHR}+\mathrm{LD}+\mathrm{PMJ}$ \\
\hline 4 & 50 & 69 & $\mathrm{~F}$ & Cuff tear arthropathy & 1 & I A & $\mathrm{HHR}+\mathrm{LD}$ \\
\hline 5 & 24 & 63 & M & Cuff tear arthropathy & 2 & I A & HHR \\
\hline 6 & 34 & 65 & $\mathrm{~F}$ & Cuff tear arthropathy & 2 & I A & $\mathrm{HHR}+\mathrm{LD}$ \\
\hline 7 & 61 & 67 & $\mathrm{~F}$ & Cuff tear arthropathy & 2 & I A & $\mathrm{HHR}+\mathrm{LD}$ \\
\hline 8 & 26 & 68 & M & Cuff tear arthropathy & 3 & I A & $\mathrm{HHR}+\mathrm{PMJ}$ \\
\hline 9 & 41 & 55 & M & Cuff tear arthropathy & 3 & I A & HHR + Cofield \\
\hline 10 & 33 & 60 & M & Cuff tear arthropathy & 3 & II A & $\mathrm{HHR}+\mathrm{LD}$ \\
\hline 11 & 24 & 64 & M & Cuff tear arthropathy & 3 & II A & $\mathrm{HHR}+\mathrm{LD}$ \\
\hline 12 & 36 & 67 & M & Cuff tear arthropathy & 1 & I A & HHR + Cofield \\
\hline 13 & 36 & 67 & M & Cuff tear arthropathy & 3 & II A & $\mathrm{HHR}+\mathrm{LD}$ \\
\hline 14 & 47 & 69 & M & Cuff tear arthropathy & 3 & I A & HHR + Cofield \\
\hline 15 & 27 & 61 & $\mathrm{~F}$ & Cuff tear arthropathy & 1 & I A & HHR + Cofield \\
\hline 16 & 54 & 58 & M & Cuff tear arthropathy & 3 & I B & $\mathrm{HHR}+\mathrm{LD}$ \\
\hline 17 & 24 & 65 & $\mathrm{~F}$ & Cuff tear arthropathy & 2 & II A & HHR \\
\hline 18 & 66 & 69 & $\mathrm{~F}$ & Cuff tear arthropathy & 1 & I A & $\mathrm{HHR}+\mathrm{LD}$ \\
\hline 19 & 31 & 68 & M & Cuff tear arthropathy & 4 & I B & HHR \\
\hline 20 & 38 & 59 & M & Cuff tear arthropathy & 2 & I A & HHR + Cofield \\
\hline 21 & 47 & 61 & M & Cuff tear arthropathy & 2 & II A & $\mathrm{HHR}+\mathrm{LD}$ \\
\hline 22 & 24 & 64 & $\mathrm{~F}$ & Cuff tear arthropathy & 3 & II A & HHR + Cofield \\
\hline 23 & 24 & 68 & M & Cuff tear arthropathy & 3 & II A & HHR + Cofield \\
\hline 24 & 24 & 69 & $\mathrm{~F}$ & Cuff tear arthropathy & 1 & I A & HHR + Cofield \\
\hline 25 & 24 & 69 & M & Cuff tear arthropathy & 4 & II A & HHR + Cofield \\
\hline
\end{tabular}

HHR: humeral head replacement; LD: latissimus dorsi transfer; PMJ: pectralis major transfer; Cofield: Subscapularis partial tendon transfer.

$138.8^{\circ}(\mathrm{P}<0.0004)$, and the $\mathrm{ER}$ improved from an average of $16.2^{\circ}$ to $33.2^{\circ}(\mathrm{P}=0.0055)$ postoperatively (Figure 4 and Table 3). No complications, such as dislocations, infections, fractures, or nerve injuries, were observed.

\section{Discussion}

Cuff tear arthropathy was introduced in 1977 by Neer [8]. Numerous studies [8]-[14] of the use of total shoulder arthroplasty and HHR for this disease have been reported. However, due to concerns over loosening of the glenoid component after total shoulder arthroplasty, HHR has become the preferred treatment. In most reports on HHR [8]-[14], complete repair of the rotator cuff was not possible; the clinical results included excellent pain relief, but only modest functional improvements.

Among the few reports describing the long-term results of HHR, Goldberg et al. [11] [12] reported the surgical techniques and their long-term results for 25 shoulders at a mean of 10 years postoperatively. None of the patients reported severe pain or underwent revision surgery for problems related to the implant. In addition, 34 shoulders were also evaluated after undergoing HHR more than two years. The shoulder with complete coverage of cuff showed a trend to improved outcomes compared with the shoulders with partial coverage. Furthermore, a humeral head implant was sized by comparing with the resected humeral head fragment, and they suggested the importance of not overstuffing the joint with a larger head. Regarding the size of the humeral head implant, Pollock et al. [13] also suggested that some looseness of fit can be tolerated, but gross instability is unacceptable. 


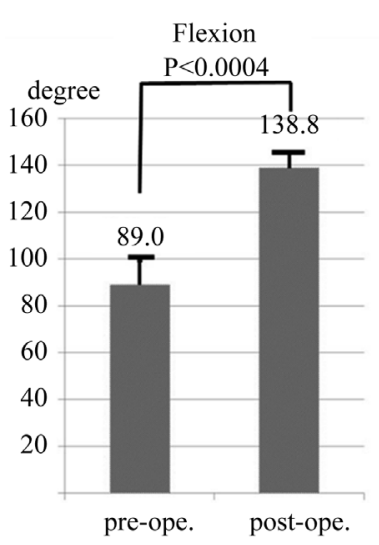

(a)

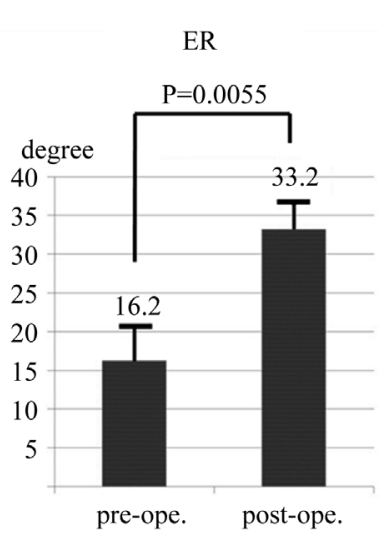

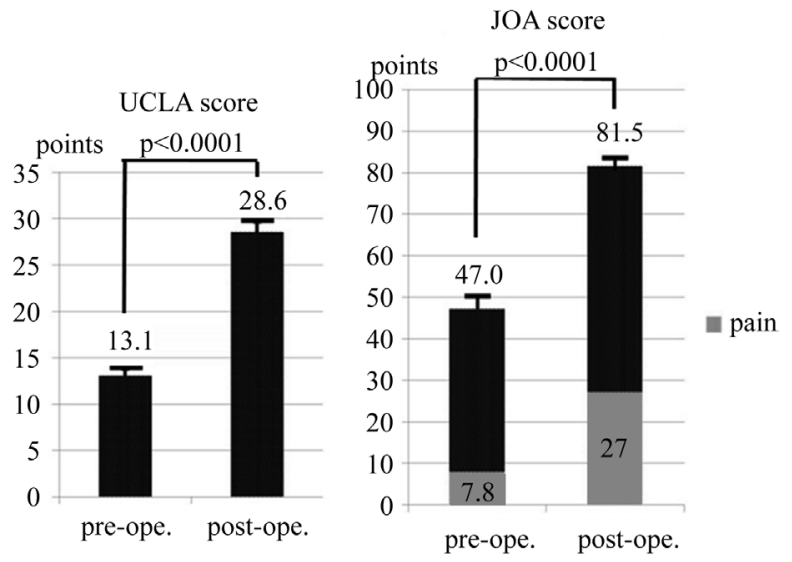

(b)

Figure 4. Results from the present study: (a) Active motion (flexion, external rotation); (b) UCLA score and JOA score.

Table 3. Clinical results of all cases.

\begin{tabular}{|c|c|c|c|c|c|c|c|c|c|c|}
\hline \multirow{2}{*}{ Case } & \multicolumn{5}{|c|}{ Pre-operation } & \multicolumn{5}{|c|}{ Post-operation } \\
\hline & UCLA score & JOA score & Flexion & ER & IR & UCLA score & JOA score & Flexion & ER & IR \\
\hline 1 & 14 & 58 & 140 & 20 & & 30 & 81.5 & 160 & 60 & Th12 \\
\hline 2 & 6 & 16 & 20 & -10 & hip & 32 & 68.5 & 160 & 10 & L1 \\
\hline 3 & 8 & 13 & 0 & 0 & thigh & 32 & 87.5 & 160 & 50 & Th12 \\
\hline 4 & 6 & 36 & 20 & 10 & hip & 32 & 85 & 165 & 45 & hip \\
\hline 5 & 13 & 54 & 115 & 25 & hip & 31 & 89 & 135 & 40 & L3 \\
\hline 6 & 11 & 26 & 60 & -20 & hip & 29 & 77 & 130 & 20 & \\
\hline 7 & 10 & 32 & 30 & 30 & L4 & 29 & 80 & 120 & 10 & L5 \\
\hline 8 & 19 & 57 & 150 & 35 & L4 & 32 & 87 & 165 & 45 & L3 \\
\hline 9 & 13 & 45 & 80 & 60 & hip & 32 & 91 & 165 & 30 & L3 \\
\hline 10 & 13 & 37 & 60 & 20 & & 26 & 70 & 150 & 30 & L3 \\
\hline 11 & 14 & 54 & 95 & 30 & L3 & 30 & 78 & 160 & 60 & L1 \\
\hline 12 & 12 & 52 & 100 & 10 & $\mathrm{~S}$ & 31 & 86 & 130 & 45 & L4 \\
\hline 13 & 11 & 33 & 50 & 30 & L1 & 18 & 66.5 & 60 & 30 & L3 \\
\hline 14 & 14 & 51 & 145 & 20 & L3 & 30 & 92 & 150 & 30 & L1 \\
\hline 15 & 13 & 42 & 95 & -15 & Th12 & 29 & 79 & 130 & 20 & L3 \\
\hline 16 & 12 & 39 & 10 & -40 & L2 & 30 & 89 & 170 & 60 & hip \\
\hline 17 & 10 & 39 & 45 & 30 & L3 & 21 & 72.5 & 100 & 30 & $\mathrm{~L} 1$ \\
\hline 18 & 17 & 61 & 165 & 45 & Th12 & 30 & 90 & 160 & 60 & Th10 \\
\hline 19 & 18 & 74 & 120 & 0 & hip & 34 & 93 & 150 & 0 & $\mathrm{~L} 1$ \\
\hline 20 & 11 & 33 & 60 & 10 & Th12 & 34 & 85 & 160 & 30 & L4 \\
\hline 21 & 15 & 55 & 130 & 10 & L1 & 16 & 69 & 45 & 20 & \\
\hline 22 & 16 & 61 & 145 & 10 & L1 & 29 & 89 & 150 & 30 & $\mathrm{~S}$ \\
\hline 23 & 18 & 76.5 & 135 & 45 & L1 & 32 & 89.5 & 150 & 30 & L3 \\
\hline 24 & 19 & 79.5 & 165 & 30 & Th10 & 30 & 84.5 & 165 & 35 & Th12 \\
\hline 25 & 14 & 52 & 90 & 20 & L3 & 16 & 59 & 80 & 10 & hip \\
\hline
\end{tabular}

ER: external rotation; IR: internal rotation; UCLA: University of California, Los Angeles; JOA: Japanese Orthopaedic Association. 
As these previous reports suggested, HHR for cuff tear arthropathy can relieve pain, but cuff function is not sufficiently restored with only repair of the torn cuff muscles that have usually developed atrophy and fatty- infiltration.

Previous studies have reported the use of various operative procedures for irreparable massive rotator cuff tears, such as the patch method, the Debeyre-Patte procedure, partial repair, arthroscopic subacromial decompression, and debridement. [15]-[17] At our institution, we have performed cuff reconstructions, combined with latissimus dorsi tendon and pectoralis major tendon transfers, as the primary option for irreparable massive rotator cuff tears, with the objective of restoring cuff function with healthy muscles instead of using deteriorated torn muscles. However, since some reports [18] [19] have found OA progression after tendon transfer in patients with cuff tear arthropathy and an irreparable rotator cuff tear with OA, we have performed HHR using a small humeral head prosthesis in addition to cuff reconstruction.

Recently, RSA has been primarily indicated for irreparable rotator cuff tears. In many reports [1]-[6] describing RSA outcomes, good improvements in flexion have been reported, with only small improvements in ER. The present study demonstrated that HHR performed using a small humeral head and cuff reconstruction for irreparable rotator cuff tear in patients less than 70 years of age provided favorable results compared with previously reported RSA results, especially with respect to ER (Table 4). Some reports indicated that complications occured in $14 \%-68 \%$ of RSA cases [3]-[6], which is a relatively high complication rate. In contrast, in the present study, dislocations, infections, fractures, nerve injuries, or other complications were not observed (Table 5).

Another advantage of our strategy is that the glenoid bone stock can be maintained after surgery. If further revision surgery is eventually required, RSA can still be considered as a reconstruction option. Since the patients included in the present study were relatively active, long-term follow-up is required to assess their continued progress.

The disadvantages of the current surgical procedure are the requirement for tendon transfers and the complicated postoperative treatment. Further follow-up is necessary to assess the long-term outcomes of the current procedure. In the present study, three patients had postoperative forward flexion of less than $90^{\circ}$. These cases were Seebauer's classification type IIA and Hamada's classification grade 3 or 4 on the X-ray evaluations. In a future study, factors contributing to the poor results of this technique should be examined.

The small number of cases, short follow-up time and the fact that glenoid wear was not evaluated are the limitations of the present study.

Table 4. Clinical results comparing the present study and RSA.

\begin{tabular}{|c|c|c|c|c|c|c|}
\hline & & \multirow{2}{*}{ Shoulders, $\mathrm{n}$} & \multirow{2}{*}{$\begin{array}{c}\text { Mean age, years } \\
\text { (range) }\end{array}$} & \multirow{2}{*}{$\begin{array}{c}\text { Follow-up } \\
\text { (months) }\end{array}$} & \multirow{2}{*}{$\begin{array}{c}\text { Flex }\left({ }^{\circ}\right) \\
\text { Pre } \rightarrow \text { post ope }\end{array}$} & \multirow[t]{2}{*}{$\operatorname{ER}\left({ }^{\circ}\right)$} \\
\hline & & & & & & \\
\hline \multirow{3}{*}{ RSA } & Wall et al. [5] & 191 & $72.7(23-86)$ & 39.9 & $86 \rightarrow \mathbf{1 3 7}$ & $8 \rightarrow 6$ \\
\hline & Werner et al. [6] & 58 & $68(44-84)$ & 38 & $42 \rightarrow \mathbf{1 0 0}$ & $17 \rightarrow \mathbf{1 2}$ \\
\hline & Sirveaux et al. [4] & 77 & $73(60-86)$ & 44.5 & $73 \rightarrow \mathbf{1 3 8}$ & $3.5 \rightarrow \mathbf{1 1 . 2}$ \\
\hline Present study & & 25 & $64.3(55-69)$ & 38.7 & $89 \rightarrow \mathbf{1 3 8 . 8}$ & $16.2 \rightarrow \mathbf{3 3 . 2}$ \\
\hline
\end{tabular}

RSA: reverse shoulder arthroplasty; Flex: flexion; ER: external rotation.

Table 5. Complications reported from RSA.

\begin{tabular}{|c|c|c|c|}
\hline & Shoulders, $\mathrm{n}$ & Complication rate $(\%)$ & Re-operation rate $(\%)$ \\
\hline Wall et al. [5] & 191 & 19 & 28 \\
\hline Werner et al. [6] & 58 & 50 & 33 \\
\hline Sirveaux et al. [4] & 80 & 16 & 3.8 \\
\hline Guery et al. [3] & 66 & 14 & 11 \\
\hline Present study & 25 & $\mathbf{0}$ & $\mathbf{0}$ \\
\hline
\end{tabular}




\section{Conclusions}

HHR using small humeral head prostheses and cuff reconstruction for irreparable massive rotator cuff tears and OA in patients less than 70 years of age showed favorable outcomes with active flexion and ER, with improvements that were greater than those reported in the previous RSA studies.

The operative procedure used in the present study is considered particularly useful in relatively young people for whom RSA is not considered to be the first option. And, with the glenoid bone stock remains, TSA or RSA can be performed as a revision surgery at a later stage.

\section{References}

[1] Boileau, P., Watkinson, D., Hatzidakis, A.M. and Hovorka, I. (2006) The Grammont Reverse Shoulder Prosthesis: Results in Cuff Tear Arthritis, Fracture Sequelae, and Revision Arthroplasty. Journal of Shoulder and Elbow Surgery, 15, 527-540. http://dx.doi.org/10.1016/j.jse.2006.01.003

[2] Favard, L., Levigne, C., Nerot, C., Gerver, C., Wilde, L.D. and Mole, D. (2011) Reverse Prostheses in Arthropathies with Cuff Tear: Are Survivorship and Function Maintained Over Time? Clinical Orthopaedics and Related Research, 469, 2469-2475. http://dx.doi.org/10.1007/s11999-011-1833-y

[3] Guery, J., Favard, L., Sirveaux, F., Oudet, D., Mole, D. and Walch, G. (2006) Reverse Total Arthroplasty: Survivorship Analysis of Eighty Replacements Followed for Five to Ten Years. The Journal of Bone and Joint Surgery, 88, 1742-1747. http://dx.doi.org/10.2106/JBJS.E.00851

[4] Sirveaux, F., Favard, L., Oudet, D., Huquet, D., Walch, G. and Mole, D. (2004) Grammont Inverted Total Shoulder Arthroplasty in the Treatment of Glenohumeral Osteoarthritis with Massive Rupture of the Cuff: Results of a Multicenter Study of 80 Shoulders. The Journal of Bone and Joint Surgery, 86, 388-395. http://dx.doi.org/10.1302/0301-620X.86B3.14024

[5] Wall, B., Nove-Josserand, L., O’Connor, D.P., Edwards, T.B. and Walch, G. (2007) Reverse Total Shoulder Arthroplasty: A Review of Results According to Etiology. The Journal of Bone and Joint Surgery, 89, 1476-1485. http://dx.doi.org/10.2106/JBJS.F.00666

[6] Werner, C.M.L., Steinmann, P.A., Gilbart, M. and Gerver, C. (2005) Treatment of Painful Pseudoparesis Due to Irreparable Rotator Cuff Dysfunction with the Delta III Reverse-Ball-and-Socket Total Shoulder Prosthesis. The Journal of Bone and Joint Surgery, 87, 1476-1486.

[7] Yamane, S., Suenaga, N., Oizumi, N. and Funakoshi, T. (2011) Total Shoulder Arthroplasty and Humeral Head Replacement for Osteoarthritis and Cuff Tear Arthropathy in Patients 75 Years Old and Older. Katakansetsu, 35, 641644.

[8] Neer, C.S. 2nd, Craig, E.V. and Fukuda, H. (1983) Cuff Tear Arthropathy. The Journal of Bone and Joint Surgery, 65, 1232-1244.

[9] Arntz, C.T., Jackins, S. and Matsen, F.A. 3rd. (1993) Prosthetic Replacement of the Shoulder for the Treatment of Defects in the Rotator Cuff and the Surface of the Glenoid Joint. The Journal of Bone and Joint Surgery, 75, 485-491.

[10] Field, L.D., Dines, D.M., Zabinski, S.F. and Warren, R.F. (1997). Hemiarthroplasty of the Shoulder for Rotator Cuff Arthropathy. Journal of Shoulder and Elbow Surgery, 6, 18-23. http://dx.doi.org/10.1016/S1058-2746(97)90066-5

[11] Goldberg, S.S., Bell, J.E., Kim, H.J., Bak, S.F., Levine, W.N. and Bigliani, L.U. (2008) Hemiarthroplasty for the Rotator Cuff-Deficient Shoulder. The Journal of Bone and Joint Surgery, 90, 554-559. http://dx.doi.org/10.2106/JBJS.F.01029

[12] Goldberg, S.S. and Bigliani, L.U. (2009) Hemiarthroplasty for the Rotator Cuff-Deficient Shoulder Surgical Technique. The Journal of Bone and Joint Surgery, 91, 22-29.

[13] Pollock, R.G., Deliz, E.D., Mcllveen, S.J., Flatow, E.L. and Bigliani, L.U. (1992) Prosthetic Replacement in Rotator Cuff Deficient Shoulders. Journal of Shoulder and Elbow Surgery, 1, 173-186. http://dx.doi.org/10.1016/1058-2746(92)90011-Q

[14] Sanchez-Sotelo, J., Cofield, R.H. and Rowland, C.M. (2001) Shoulder Hemiarthroplasty for Glenohumeral Arthritis Associated with Severe Rotator Cuff Deficiency. The Journal of Bone and Joint Surgery, 83-A, 1814-1822.

[15] Duralde, X.A. and Bair, B. (2005) Massive Rotator Cuff Tears: The Result of Partial Rotator Cuff Repair. Journal of Shoulder and Elbow Surgery, 14, 121-127. http://dx.doi.org/10.1016/j.jse.2004.06.015

[16] Ha'eri, G.B. and Wiley, A.M. (1981) Advancement of the Supraspinatus Muscle in the Repair of Ruptures of the Rotator Cuff. The Journal of Bone and Joint Surgery, 63, 232-238.

[17] Labbe, M.R. (2006) Arthroscopic Technique for Patch Augmentation of Rotator Cuff Repairs. Arthroscopy, 22, 1136.e1-1136.e6. 
N. Miyoshi et al.

[18] Aoki, M., Okamura, K., Fukushima, S., Takahashi, T. and Ogino, T. (1996) Transfer of Latissimus Dorsi for Irreparable Rotator-Cuff Tears. The Journal of Bone and Joint Surgery, 78-B, 761-766.

[19] Gerber, C. (1992) Latissimus Dorsi Transfer for the Treatment of Irreparable Tears of the Rotator Cuff. Clinical Orthopaedics and Related Research, 275, 152-160 
Scientific Research Publishing (SCIRP) is one of the largest Open Access journal publishers. It is currently publishing more than 200 open access, online, peer-reviewed journals covering a wide range of academic disciplines. SCIRP serves the worldwide academic communities and contributes to the progress and application of science with its publication.

Other selected journals from SCIRP are listed as below. Submit your manuscript to us via either submit@scirp.org or Online Submission Portal.
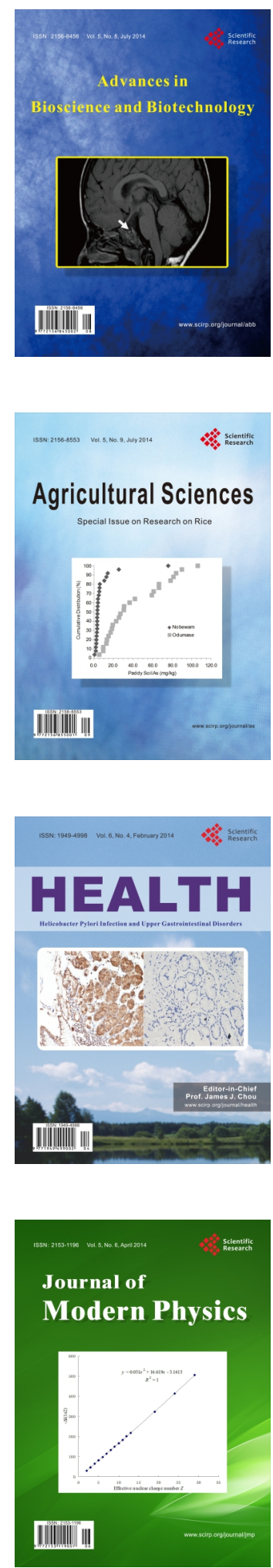
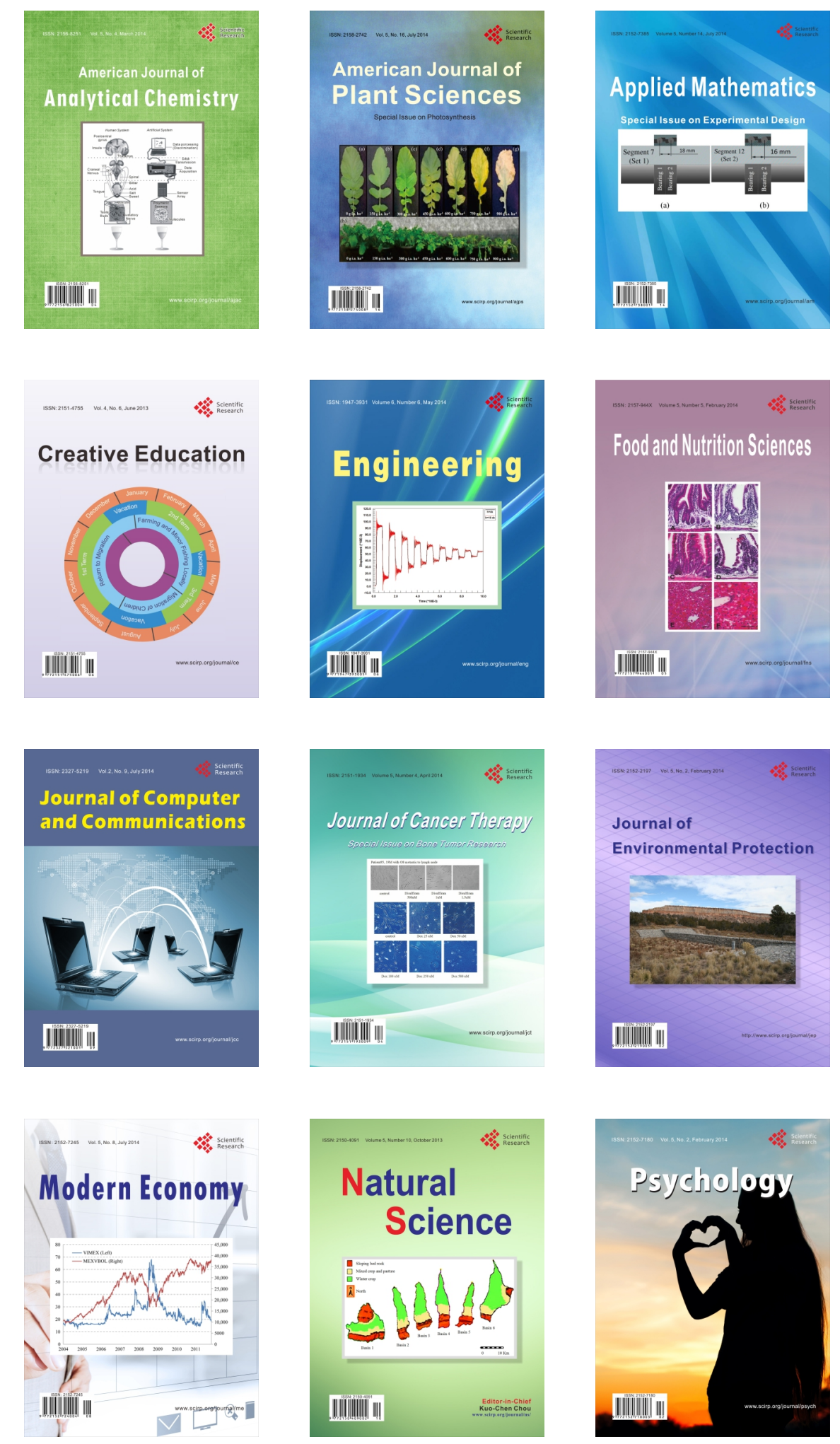